\title{
Synthetic fibers in atmospheric fallout: a source of microplastics in the environment?
}

\author{
Rachid Dris $^{1 *}$, Johnny Gasperi ${ }^{1 /}$, Mohamed Saad ${ }^{1}$, Cécile Mirande ${ }^{1}$, Bruno Tassin ${ }^{1}$ \\ ${ }^{1}$ Université Paris-Est, LEESU (laboratoire eau environnement et systèmes urbains), 61 avenue du Général de Gaulle, 94010 \\ Créteil Cedex, France \\ *drisr@leesu.enpc.fr \\ \#gasperi@u-pec.fr
}

\begin{abstract}
Sources, pathways and reservoirs of microplastics, plastic particles smaller than $5 \mathrm{~mm}$, remain poorly documented in an urban context. While some studies pointed out wastewater treatment plants as a potential pathway of microplastics, none have focused on the atmospheric compartment. In this work, the atmospheric fallout of microplastics was investigated in two different urban and sub-urban sites. Microplastics were collected continuously with a stainless steel funnel. Samples were then filtered and observed with a stereomicroscope. Fibers accounted for almost all the microplastics collected. An atmospheric fallout between 2 and 355 particles $/ \mathrm{m}^{2} /$ day was highlighted. Registered fluxes were systematically higher at the urban than at the sub-urban site. Chemical characterization allowed to estimate at $29 \%$ the proportion of these fibers being all synthetic (made with petrochemicals), or a mixture of natural and synthetic material. Extrapolation using weight and volume estimates of the collected fibers, allowed a rough estimation showing that between 3 and 10 tons of fibers are deposited by atmospheric fallout at the scale of the Parisian agglomeration every year $\left(2500 \mathrm{~km}^{2}\right)$. These results could serve the scientific community working on the different sources of microplastic in both continental and marine environments.
\end{abstract}

\section{KEYWORDS}

Microplastics; Urban environment; Atmospheric fallout; Microplastic sources; Synthetic fibers. 


\section{INTRODUCTION}

Microplastics are a widespread particular contaminant originating from the breakdown of larger plastic debris (secondary) or directly manufactured on a millimetric or submilletric size (primary) (Cole et al., 2011). These plastics have been defined as particles with the largest dimension smaller than $5 \mathrm{~mm}$ (Arthur et al., 2008); they cover a continuous spectrum of sizes and shapes including 1D-fibers, 2Dfragments and 3D-spheres.

Given their size, these microparticles can be ingested by a wide range of species, either in marine (Anastasopoulou et al., 2013; Lusher et al., 2013; Thompson et al., 2004) or freshwater environnements (Sanchez et al., 2014). These microplastics have negative effects on organisms and the possibility of their translocation, bioaccumulation and trophic accumulation is currently being debated (Wright et al., 2013).

While marine plastic pollution has been well documented, there has been limited focus on the continental contamination (Dris et al., 2015b; Wagner et al., 2014). Moreover, its sources, pathways and reservoirs in urban environments remain largely unknown. It is crucial to gather a better knowledge about these particles in the continental environment as rivers are said to be the main source of marine microplastics (Andrady, 2011). If it is very often cited that $80 \%$ of the fibers in the marine environment come from the continent, this estimation is not well documented and demonstrated.

Synthetic fibers are one of the forms in which microplastics can be found. They derive presumably from synthetic clothing or macroplastics. Different pathways are thought to be an important source of fibrous microplastics in the aquatic environment. It has been shown that laundry washing machines discharge large amounts of microplastics into wastewaters (reaching 1900 fibers in one wash (Browne et al., 2011)). During wastewater treatment, synthetic fibers are known to contaminate sewage sludge (Habib et al., 1998; Zubris and Richards, 2005). The sources and fate of microplastics in the various compartment of the urban environment are poorly documented (Dris et al., 2015a); this paper focuses 
on the atmospheric compartment and investigates the contribution of the atmospheric fallout as a potential vector of plastic pollution.

\section{MATERIALS AND METHODS}

Total atmospheric fallout was collected on two sampling sites: one in a dense urban environment $\left(48^{\circ} 47^{\prime} 17.8^{\prime \prime} \mathrm{N}, 2^{\circ} 26^{\prime} 36.2^{\prime \prime} \mathrm{E}\right.$ - Site 1 - Figure 1$)$ and one in a less dense sub-urban environment. $\left(48^{\circ} 50^{\prime} 27.8^{\prime \prime} \mathrm{N}, 2^{\circ} 35^{\prime} 15.3^{\prime \prime} \mathrm{E}\right.$ - Site 2 - Figure 1). Site 1 was monitored over a period of one year (February $19^{\text {th }} 2014$ to March $12^{\text {th }} 2015$ ) and site 2 for a shorter period from October $3^{\text {rd }}$ to $12^{\text {th }}$ March 2015. Site 1 is localized in an area of 7900 inhabitants $/ \mathrm{km}^{2}$ while site 2 is characterized by a surrounding population of 3300 inhabitants/km² (“Insee - Régions, départements et villes de France," 2011).

The sampling surface was $0.325 \mathrm{~m}^{2}$ allowing for total atmospheric fallout (dry and wet deposition) to be collected through a stainless steel funnel. A $20 \mathrm{~L}$ glass bottle was placed at the bottom of the funnel in an opaque box to collect the water. The samples were collected at various frequencies during the monitoring period depending on cumulative rainfall leading to 24 samples at site 1 and 9 at site 2 . When both sites were monitored, the collection of samples was carried out the same day for both sites in order to allow comparison. No interruption of the sampling occurred during the whole monitoring period in each site, providing a full view of the annual variability of the atmospheric fallout.

Each time the atmospheric fallout was collected, the funnel was rinsed with $3 * 1 \mathrm{~L}$ of reverse osmosed water in order to recover all particles adhering to the funnel. As commonly done in studies focusing on the pollutant fluxes in atmospheric fallout, preliminary tests demonstrated the efficiency of such rinses. Consecutive rinses with $1 \mathrm{~L}$ showed that in the fourth rinse, the number of microplastics is similar to the one in the laboratory blanks. After the rinsing step, samples were immediately covered until the processing step to avoid any contamination. Given the sampling period and the collecting surface area, the atmospheric fallout is expressed as a number of particles per square meter per day. The rainfall was recorded for both sites. 
All samples were filtered on quartz fiber GF/A Whatman filters $(1.6 \mu \mathrm{m})$. To minimize post-sampling contamination from indoor air, samples were always covered. The filters and the vessel were heated to $500^{\circ} \mathrm{C}$ prior to their use. All laboratory procedures were performed wearing a cotton laboratory coat. Laboratory blanks were performed to verify that no microplastics are added to the samples during the laboratory procedures. Globally, blank results do not reveal any significant contamination in comparison to the levels found in samples ( 1 to 2 fibers per filter, representing between 0.5 and $5 \%$ of the fibers on the samples).

Filters were observed with a stereomicroscope (Leica MZ12). Previously used criteria were employed in order to identify synthetic fibers (Dris et al., 2015a; Hidalgo-Ruz et al., 2012; Norén, 2007). The accuracy of the method was estimated by comparing the counting of 3 different observers on the same filters. No difference $>5 \%$ in the total number of fibers was observed. In 11 of the collected samples, the length of the fibers was measured during the counting (the software "Histolab" coupled with the stereomicroscope). The observation size limit was defined to $50 \mu \mathrm{m}$.

Atmospheric fallout in this study is presented as a number of total fibers. Chemical characterization was also performed. A subsample of $n=24$ fibers was analyzed with Fourier Transform infrared (FT-IR) micro spectroscopy (Microscope LUMOS FT-IR - Brucker) coupled with an ATR (Attenuated Total Reflectance) accessory in order to characterize the proportion of synthetic and natural fibers and identify the predominant plastic polymers. The fibers were categorized according to the classification proposed by the international organization for standardization (ISO/TR 11827:2012 Textiles Composition testing - Identification of fibers).

\section{RESULTS AND DISCUSSION}

Based on a long term monitoring (one year), our results show large amounts of fibers in the atmospheric fallout, which has not yet been reported in the literature. Throughout the year of monitoring (site 1), the atmospheric fallout ranged from 2 to 355 particles $/ \mathrm{m}^{2} /$ day (Figure 2 ) with an average atmospheric fallout of $110 \pm 96$ particles $/ \mathrm{m}^{2} /$ day (mean $\pm \mathrm{SD}$ ), indicating a high annual 
variability. On Site 2 (6-month monitoring), the atmospheric fallout was around $53 \pm 38$ particles $/ \mathrm{m}^{2} /$ day (mean $\pm \mathrm{SD}$ ).

Figure 3 illustrates the proportion of fibers belonging to each size range considered for 11 samples. It can be seen that the smallest fibers (in the $200-400 \mu \mathrm{m}$ and $400-600 \mu \mathrm{m}$ size ranges) are predominant while fibers in the larger size ranges are rare. Few fibers have been found in the $50 \mu \mathrm{m}-$ $200 \mu \mathrm{m}$ size range. Fibers smaller than $<50 \mu \mathrm{m}$ are also observed with the stereomicroscope, but since their nature can be hardly identified, they were not taken into account. The length of the fibers was measured during counting. The diameter of the fibers varies mainly between 7 and $15 \mu \mathrm{m}$.

Rainfall seems to be an important factor influencing the fallout flux. In fact, particularly low numbers of fibers were found during dry weather or low cumulated rainfall periods. For rainfall between 0 and $0.2 \mathrm{~mm} /$ day, an atmospheric fallout between 2 and 34 particles $/ \mathrm{m}^{2} /$ day was recorded. During rainy periods (from 2 to $5 \mathrm{~mm} /$ day), highly variable levels of atmospheric fallout were encountered ranging from 11 to 355 particles $/ \mathrm{m}^{2} /$ day. No significant correlation between the levels of fibers in atmospheric fallout and the mean daily rainfall was highlighted. The same conclusion is obtained by considering the cumulative rainfall and the total amount of fibers collected. This indicates that if the absence of rain limits the microplastics atmospheric fallout, rainfall height is a significant factor, though not the only one, contributing to fallout variability; other mechanisms and temporal conditions also contribute to the fallout flux, but remain to be identified.

When the levels on both sites are compared side by side, it can be seen that through all the monitoring periods, the sub-urban site systematically showed fewer fibers then the urban one (Figure 4). Statistical tests showed a significant difference between the atmospheric fallout on the urban and the sub-urban site (Wilcoxon matched pairs test, confidence level of $5 \%$, $p_{\text {value }}=0.007$ ). One of the reasons that could explain this difference is the density of the surrounding population, which is considered as a proxy of 
the local activity. This is a pilot study as it contains only two sampling locations leading to a limited statistical power.

Fourier Transform infrared (FT-IR) spectroscopy showed that half of the analyzed fibers are natural fibers (50\%) being mainly cotton or wool. The remaining fibers are man-made. For $21 \%$ of the total fibers, they are manufactured by transformation of natural polymers (rayon or acetate from cellulose). In an other hand, $17 \%$ of the fibers corresponds to purely synthetic fibers, mainly polyethyleneterephthalate and only one fiber of polyamide. The other $12 \%$ fibers are made with a mixture of different materials including purely synthetic materials fibers (mixture of polyethylene-terephthalate and polyurethane) and fibers being a mixture of natural and synthetic materials (cotton and polyamide). Therefore, petrochemicals are found in $29 \%$ of the analyzed fibers in atmospheric fallout. Given the lack of studies and data addressing the issue of plastic sources and fluxes in an urban area, it is hard to evaluate the importance of the atmospheric fallout as a source of microplastics. According to the average atmospheric flux of total fibers on each site (110 and 53 particles $/ \mathrm{m}^{2} /$ day), the length of the fibers (Figure 3), their approximated section $\left(80 \mu \mathrm{m}^{2}\right.$ ), the mass of fibers in the atmospheric fallout per year may be assessed. Two densities were considered : 1 for the polyamide and $1.45 \mathrm{~g} / \mathrm{cm}^{3}$ for the polyethylene-terephthalate, corresponding to two low and heavy plastic polymers widely used in the textile industry (Hidalgo-Ruz et al., 2012). At the scale of the Parisian agglomeration (area around $2500 \mathrm{~km}^{2}$ ), it was estimated that between 3 and 10 tons of synthetic fibers, including microplastics, could originate annually from the atmosphere.

\section{CONCLUSIONS}

These results show a significant amount of fibers in atmospheric fallout, which leads to the hypothesis that the atmospheric compartment should not be neglected as a potential source of microplastics, specially knowing that we estimated at $29 \%$, the amount of these fibers containing at least partially plastic polymers. These microplastics have different possible sources: synthetic fibers from clothes and houses, degradation of macroplastics, landfills or waste incineration. The characterization indicates that the hypothesis of the clothing being the main source of these fibers is the more plausible. These 
fibers in the atmosphere, including microplastics, could be transported by wind to the aquatic environment (Free et al., 2014) or deposited on surfaces of cities or agrosystems. After deposition, they could impact terrestrial organisms or be transported into the aquatic systems through the runoff. More work is needed in order to investigate these atmospheric fibers and understand where they come from, where they end up and which mechanisms and factors lead to their transport and their fallout.

The micro IR-TF spectroscopy analysis shows the presence of microplastic fibers in the atmospheric fallout. Nevertheless, some questions arise regarding the definition of microplastics in relation with their nature and the ISO classification. Only fibers made of petrochemicals are generally considered in the literature as microplastics (Song et al., 2015). Authors think that fibers made of a mixture of natural and synthetic materials should be also included in the identification of microplastics. Further discussions are also needed to identify if artificial fibers, which are manufactured by transformation of natural polymers, could be included in microplastics. In fact, these fibers might also be prevalent in marine and continental environments and could cause physical impacts on organisms. Moreover, harmful additives and dyes can be used when manufacturing these fibers.

Furthermore, this study could serve the implementation of the marine strategy framework directive (MSFD) (Galgani et al., 2013) aiming to achieve by 2020 the good environmental status for European marine waters. The indicator 10 of the MSFD related to marine liter with a focus on microplastics indicates that the solution for marine plastic pollution is to tackle the problem at its source. This work does not aim to provide accurate atmospheric fluxes for microplastics as a lot of uncertainties remain and more studies are needed, but serves to highlight the important role that this source could play in continental and marine environments and encourages scientists to take it into consideration in future works.

\section{ACKNOWLEDGMENTS}

We address sincere thanks to the members of the LISA (Laboratoire Interuniversitaire des Systèmes Atmosphériques), especially Anne Chabas. The PhD of Rachid Dris is funded by the region Île-de-France 
Research Network on Sustainable Development (R2DS Ile-de-France). We thank Kelsey Flanagan for

lingual improvements on the manuscript. We thank the members of the ICMPE (Institut de Chimie et

des Materiaux Paris-Est) especially Mohamed Guerrouache and Valérie Langlois. We also thank

Ludovic Lemee and Gregory Candor from Brucker Optics.

\section{References}

Anastasopoulou, A., Mytilineou, C., Smith, C.J., Papadopoulou, K.N., 2013. Plastic debris ingested by deepwater fish of the Ionian Sea (Eastern Mediterranean). Deep Sea Res. Part Oceanogr. Res. Pap. 74, 11-13. doi:10.1016/j.dsr.2012.12.008

Andrady, A.L., 2011. Microplastics in the marine environment. Mar. Pollut. Bull. 62, $1596-1605$. doi:10.1016/j.marpolbul.2011.05.030

Arthur, C., Baker, J., Bamford, H., 2008. Proceedings of the International Research. Presented at the Worshop on the Occurence, Effects and Fate of Microplastic Marine Debris. Sept 9-11 2008. NOAA Technical Memorandum NOS-OR\&R-30.

Browne, M.A., Crump, P., Niven, S.J., Teuten, E., Tonkin, A., Galloway, T., Thompson, R., 2011. Accumulation of Microplastic on Shorelines Woldwide: Sources and Sinks. Environ. Sci. Technol. 45, 9175-9179. doi:10.1021/es201811s

Cole, M., Lindeque, P., Halsband, C., Galloway, T.S., 2011. Microplastics as contaminants in the marine environment: A review. Mar. Pollut. Bull. 62, 2588-2597. doi:10.1016/j.marpolbul.2011.09.025

Dris, R., Gasperi, J., Rocher, V., Saad, M., Renault, N., Tassin, B., 2015a. Microplastic contamination in an urban area: a case study in Greater Paris. Environ. Chem. 12, 592-599.

Dris, R., Imhof, H., Sanchez, W., Gasperi, J., Galgani, F., Tassin, B., Laforsch, C., 2015b. Beyond the ocean: Contamination of freshwater ecosystems with (micro-) plastic particles. Environ. Chem. 12, 539_ 550.

Free, C.M., Jensen, O.P., Mason, S.A., Eriksen, M., Williamson, N.J., Boldgiv, B., 2014. High-levels of microplastic pollution in a large, remote, mountain lake. Mar. Pollut. Bull. 85, 156-163. doi:10.1016/j.marpolbul.2014.06.001

Galgani, F., Hanke, G., Werner, S., De Vrees, L., 2013. Marine litter within the European Marine Strategy Framework Directive. ICES J. Mar. Sci. 70, 1055-1064. doi:10.1093/icesjms/fst122

Habib, D., Locke, D.C., Cannone, L.J., 1998. Synthetic fibers as indicators of municipal sewage sludge, sludge products, and sewage treatment plant effluents. Water. Air. Soil Pollut. 103, 1-8.

Hidalgo-Ruz, V., Gutow, L., Thompson, R.C., Thiel, M., 2012. Microplastics in the Marine Environment: A Review of the Methods Used for Identification and Quantification. Environ. Sci. Technol. 46, 3060-3075. doi:10.1021/es2031505

Insee - Régions, départements et villes de France [WWW Document], 2011. URL http://www.insee.fr/fr/themes/theme.asp?theme=1\&sous_theme=2 (accessed 5.22.15).

Lusher, A.L., McHugh, M., Thompson, R.C., 2013. Occurrence of microplastics in the gastrointestinal tract of pelagic and demersal fish from the English Channel. Mar. Pollut. Bull. 67, $94-99$. doi:10.1016/j.marpolbul.2012.11.028

Norén, F., 2007. Small plastic particles in Coastal Swedish waters - Kimo reports. http://www.kimointernational.org/WebData/Files/Small\%20plastic\%20particles\%20in\%20Swedi sh\% 20West\% 20Coast\%20Waters.pdf.

Sanchez, W., Bender, C., Porcher, J.-M., 2014. Wild gudgeons (Gobio gobio) from French rivers are contaminated by microplastics: Preliminary study and first evidence. Environ. Res. 128, 98-100. doi:10.1016/j.envres.2013.11.004

Song, Y.K., Hong, S.H., Jang, M., Han, G.M., Rani, M., Lee, J., Shim, W.J., 2015. A comparison of microscopic and spectroscopic identification methods for analysis of microplastics in environmental samples. Mar. Pollut. Bull. doi:10.1016/j.marpolbul.2015.01.015

Thompson, R.C., Olsen, Y., Mitchell, R.P., Davis, A., Rowland, S.J., John, A.W., McGonigle, D., Russell, A.E., 2004. Lost at sea: where is all the plastic? Science 304, 838-838. doi:10.1126/science.1094559

Wagner, M., Scherer, C., Alvarez-Muñoz, D., Brennholt, N., Bourrain, X., Buchinger, S., Fries, E., Grosbois, C., Klasmeier, J., Marti, T., Rodriguez-Mozaz, S., Urbatzka, R., Vethaak, A.D., Winther-Nielsen, 
M., Reifferscheid, G., 2014. Microplastics in freshwater ecosystems: what we know and what we need to know. Environ. Sci. Eur. 26, 1-9. doi:10.1186/s12302-014-0012-7

Wright, S.L., Thompson, R.C., Galloway, T.S., 2013. The physical impacts of microplastics on marine organisms: A review. Environ. Pollut. 178, 483-492. doi:10.1016/j.envpol.2013.02.031

Zubris, K.A.V., Richards, B.K., 2005. Synthetic fibers as an indicator of land application of sludge. Environ. Pollut. 138, 201-211. doi:10.1016/j.envpol.2005.04.013 


\section{FIGURES CAPTIONS}

Figure 1: Localization, sampling device and synthetic fibers for each site

Figure 2: Atmospheric fallout of microplastics on the site 1 in parallel with daily rainfall

Figure 3: Size distribution of synthetic fibers in 11 atmospheric fallout samples (site 1). Boxplots are plotted from bottom to top with: [ Lower quartile - $1.5^{*}$ Interquartile range ], [ Lower quartile ], [ Median ], [ Upper quartile ], [ Upper quartile $+1.5 *$ Interquartile range ]. Outliers are displayed as isolated points.

Figure 4: Atmospheric fallout of microplastics on an urban site (site 1) and a sub-urban site (site 2) 


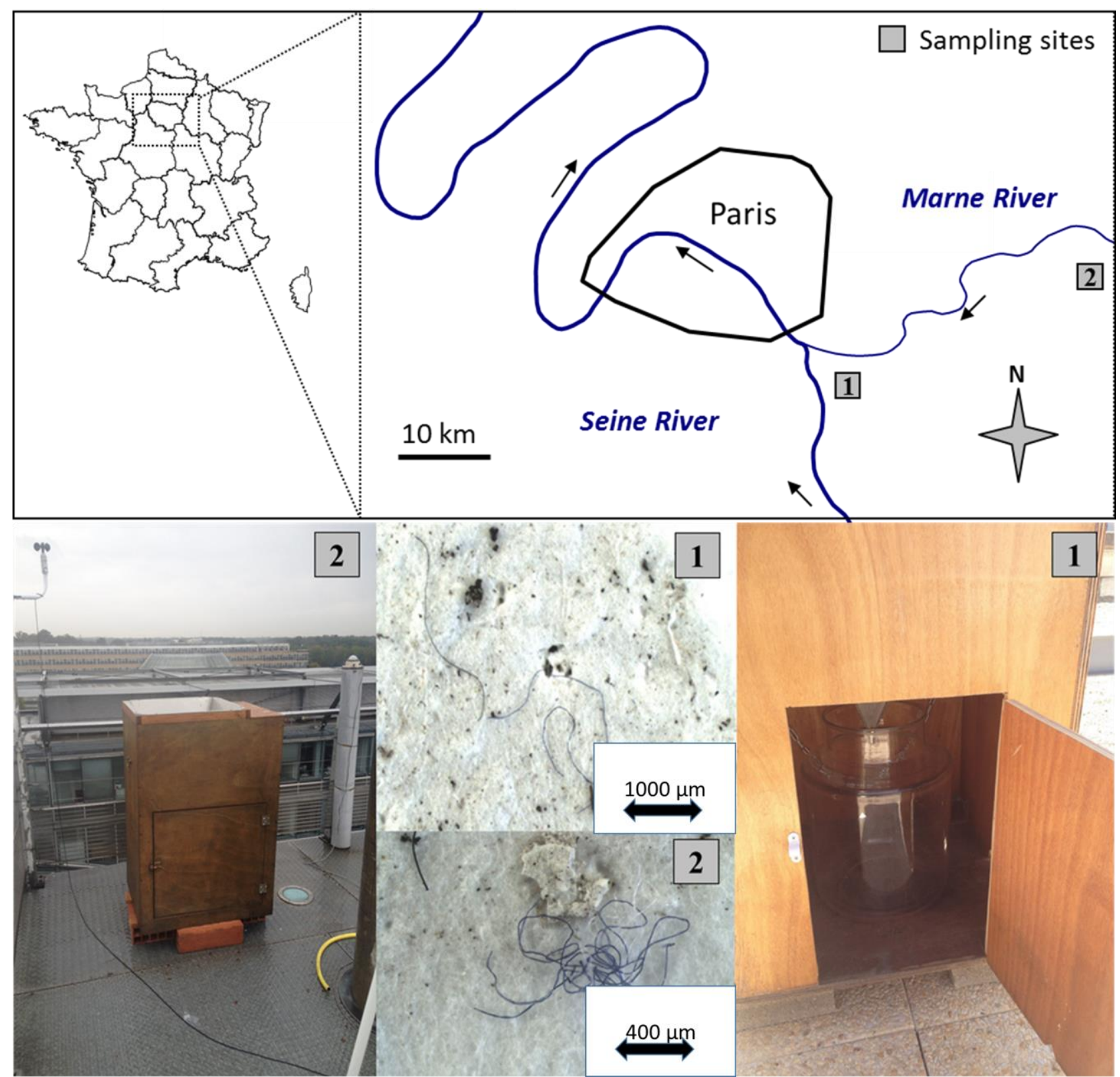

Figure 1 


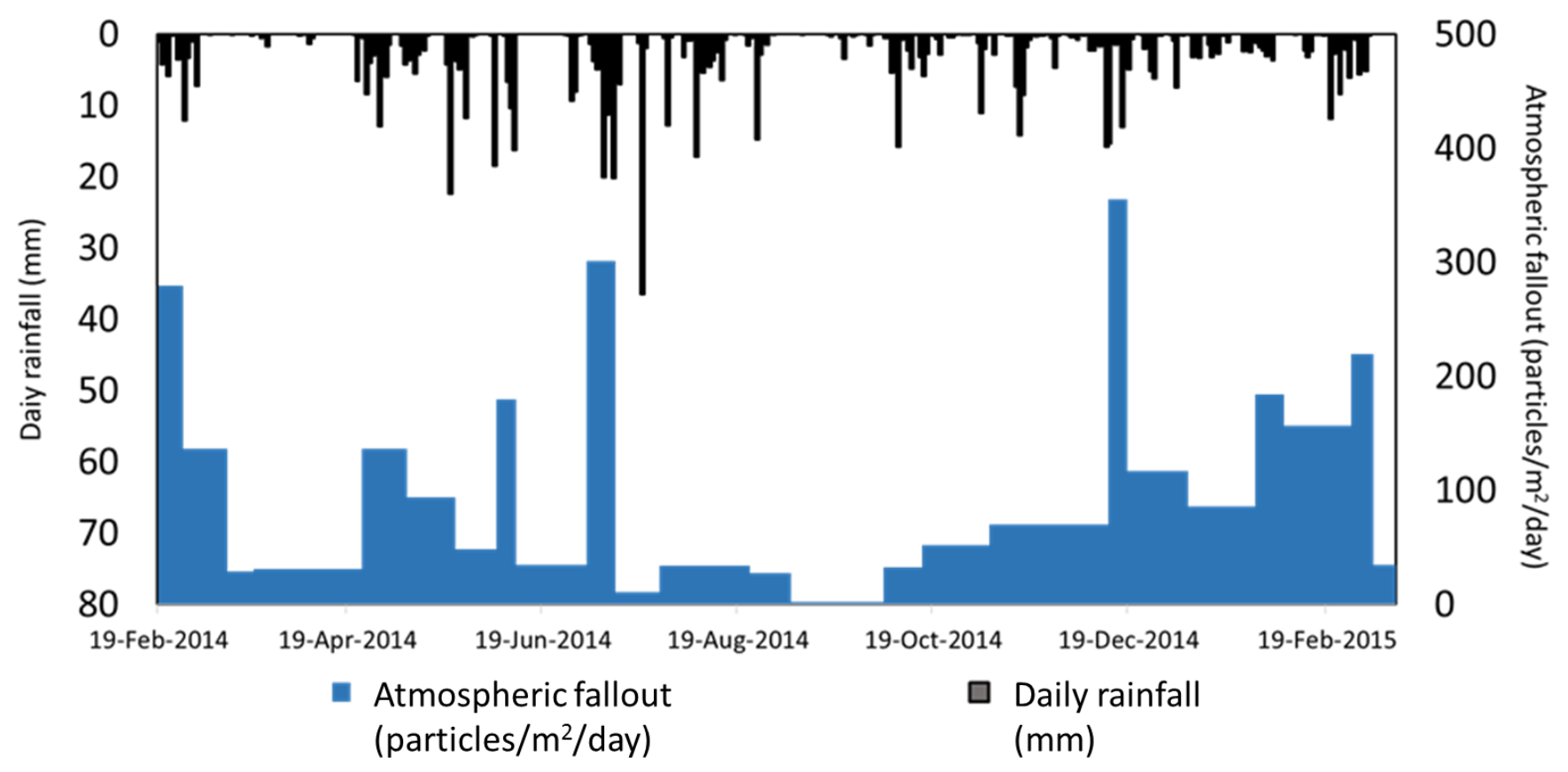

Figure 2 


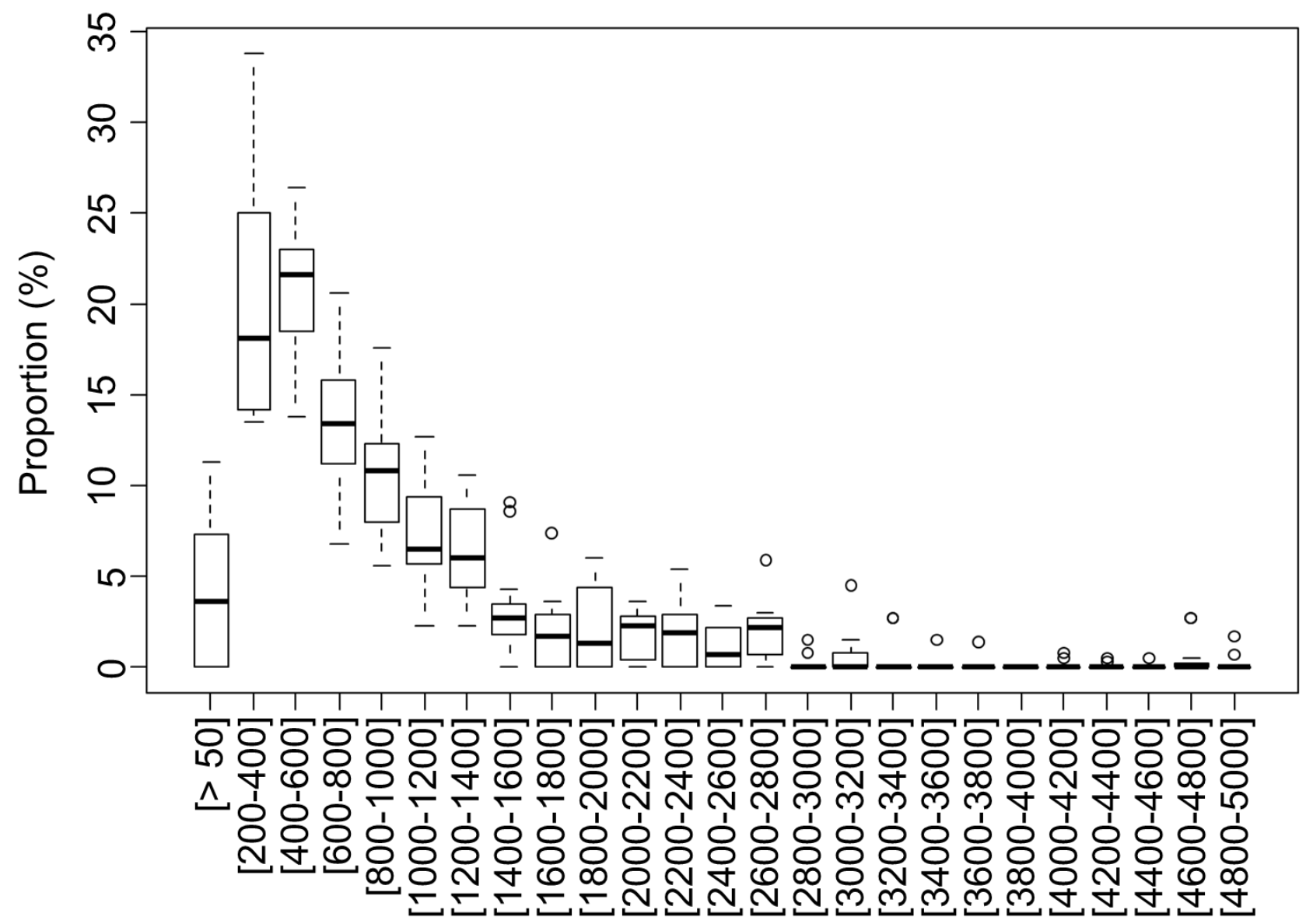

Fibers length $(\mu \mathrm{m})$

Figure 3 


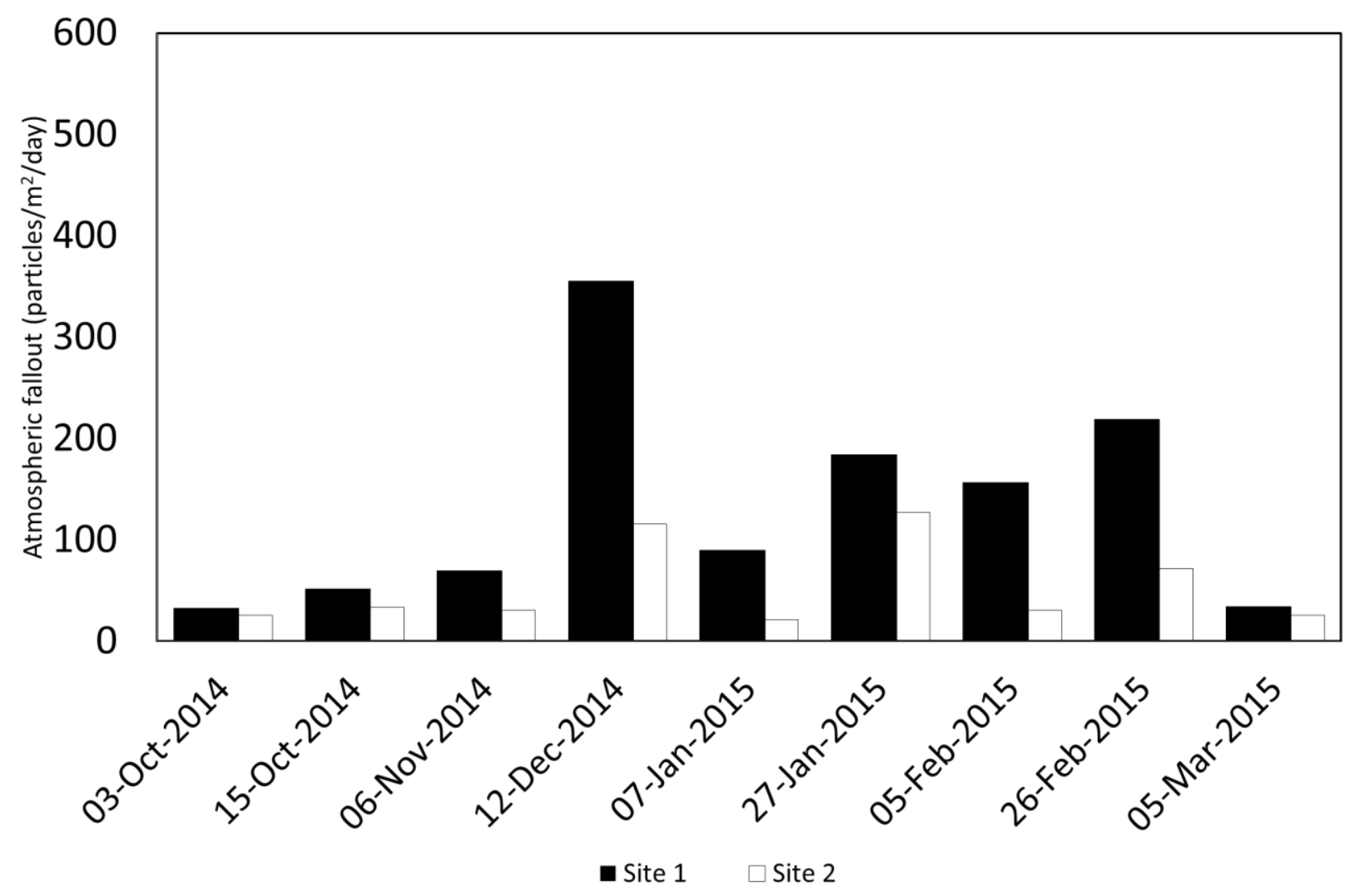

Figure 4 